\title{
Problems of Intertextuality in Audio-Visual Arts
}

\author{
Halyna M. Kot ${ }^{1}$, Olena G. Levchenko', Tetiana O. Kravchenko², \\ Oksana S. Musiienko ${ }^{3}$ \& Kostiantyn V. Hrubych ${ }^{1}$ \\ ${ }^{1}$ Department of Tele-Journalism and Actor's Skill, Kyiv National University of Culture and \\ Arts, Kyiv, Ukraine \\ ${ }^{2}$ Department of Scenic Speech, Kyiv National I.K. Karpenko-Kary Theatre, Cinema and \\ Television University, Kyiv, Ukraine \\ 3Department of Cinematography, Kyiv National I.K. Karpenko-Kary Theatre, Cinema and \\ Television University, Kyiv, Ukraine \\ Contact: kot5382-6@nuos.pro
}

\begin{abstract}
At the present stage, the visualisation process covers all areas of life that come into contact with information and its presentation. Specialists and researchers in the relevant fields of activity are increasingly using the concepts that have been formed on the basis of printed text in the audio-visual arts. Such an example is the use of intertextuality, which is currently one of the promising areas for research on the example of audio and visual material (film, video, music, photography). The aim of the study was to identify the main current problems of the use of intertextuality in the audio-visual arts on the example of the two most common forms - film and music. The main methods used in this work are intertextual analysis, as well as discourse analysis, because for this method the area of interest is the study of discourse changes associated with intertextuality. As a result of the analysis, it was found that one of the problems of intertextuality is the uncertainty and lack of unity in its understanding between the followers of different approaches to the doctrine of intertext; several problems were identified. The authors propose solutions to the identified problems of the theory of intertextuality in the audio-visual arts, which confirms the practical significance of the study.
\end{abstract}

Keywords: text borrowing, film, music, culture studies, intertextual interactions.

\section{Introduction}

Nowadays, there are many forms of fixing the text - from printed publications to ordinary everyday conversations, and the very understanding of the text has long meant more than the actual verbal expression. The text recognises semiotically complicated, iconic and other forms of semantic units. One of the global textual categories, which testifies to its presence in various postmodern texts, is called the category of intertextuality. Different approaches to the definition of intertextuality are due to many areas of manifestation of this phenomenon, as well as different scientific tasks of researchers in scientific research. In general, intertextuality is understood as a general property of texts, which is expressed in the presence of links between them, through which texts (or parts of them) are able in various ways to explicitly or implicitly refer to each other. The concept of intertextuality is relatively new and unexplored. It was first used by poststructuralist theorist Julia Kristeva (1967) to denote the general property of texts, reflected in the existence of connections between them, through which texts or parts of them can refer to each other. But the idea of dialogue

(C) AesthetixMS 2021. This Open Access article is published under a Creative Commons Attribution Non-Commercial 4.0 International License (http://creativecommons.org/licenses/by-nc/4.o/), which permits non-commercial re-use, distribution, and reproduction in any medium, provided the original work is properly cited. For citation use the DOI. For commercial re-use, please contact editor@rupkatha.com. 
between different texts was first expressed by the Russian philosopher, culture scientist and literary critic Mikhail Bakhtin, whose idea was later developed and formed by Kristeva (Bakhtin, 1929). Currently, the theory of intertextuality is in its infancy, so the problematic issues that cover this linguistic category are becoming relevant. For half a century the nature of the origin and existence of intertextuality and intertext has been studied, which were considered from the standpoint of various sciences: philosophy, culture studies, linguistics, philology, etc. Specialists discuss the basic and individual representatives of the theory of intertextuality. For example, the boundaries of text and intertext, allusions and reminiscences, the relationship between the concepts of work, text, intertext, discourse and others, the role of the recipient and the author within the intertext, etc.

In addition, in recent years there have been dissertations, books and articles with a marked tendency to summarise, comprehend and systematise the theory and practice of the study of intertextuality, its constituents and tools of analysis. Thus, in the doctoral dissertation, T.E. Litvinenko is dominated by the desire to complete discussions on the above issues. In her work she writes the following: “... all texts can be called intertext, although the detection of this feature in the text structure inevitably becomes a factor in their re-categorisation, as the presence of intertextual links destroys the postulated linearity of the text, transforming it from formal to integral discursive product" (Litvinenko, 2008).

The intertextuality as a conscious attitude of the author to construct connections between his work and other texts was studied by such authors as M.A. Fateeva (2006), N.A. Kuzmina (2004), V.Ye. Chernyavska (2004), Ye.A. Bazhenova (2003), I.V. Arnold (1999), who proposed more specific and therefore more suitable for the purposes of linguistic and literary analysis of the definition. Among foreign scholars who have studied intertextuality and tried to stabilise its meaning, the following should be singled out: J. Jennett (1999), M. Riffaterre (1988), G. Plett (1991) and others. One of the objects of this research is the use of intertext in cinema. The intertextual relationships of films made within a particular culture are usually not relevant to the perception of these films by a foreign audience and therefore require a comment. The linguacultural procedure of such comments has not yet been developed in the science of language. Feature film as a type of text is associated with different types of texts (cultural phenomena), and this issue needs to be studied. Another object of this research is intertext in music. The phenomenon of interpretation of a musical work also has an intertextual nature, and multiplicatively combines in the act of performance (interpretation) of music the intentions of the musical text, the subjective biophysiological and psychological intentions of a performer in combination with social conditions of interpretation.

Therefore, the aim of the study is to identify the main current problems of the use of intertextuality in the audio-visual arts on the example of the two most common forms - cinema and music.

\section{Materials and methods}

The main methods used in this work were intertextual analysis, as well as discourse analysis, because for this method the area of interest is the study of discourse changes associated with intertextuality. The theory of intertextuality is essentially the basis for intertextual analysis of the text. This analysis is conducted, as a rule, from different positions depending on the field of knowledge in the study of which it is used: art history, linguistics, culture studies.

The purpose of discursive analysis is to study the language used by members of a particular language community. As part of this study, the authors examine the discourse used in the audio- 
visual arts. Discourse analysis is a way to understand an "idea" of s text, a set of ideas and beliefs with which the author explains and shapes reality. In a general sense, discourse analysis is a structural-semiotic study of texts and reactions of the recipient to them. In the process of such analysis, the hidden meanings of the text, the context of its creation, probable interpretations by a reader/listener, etc. are investigated. There is no single version of discourse analysis, so it can be applied to both natural and specially created forms of text translation. Words are more amenable to analysis, they can be combined, divided into subgroups, divided into semiotic segments, can be arranged in such a way as to allow a researcher to compare, contrast, analyse and search for specific models. Due to the property of discourse to adapt to different forms of text, this type of analysis has been chosen for research.

The works of domestic and foreign authors in the field of theory and history of culture, philosophy, semiology, history and theory of cinema and music, among which special emphasis was placed on theoretical and methodological aspects of late classical science, formed the theoretical and methodological basis that allowed:

- making a comprehensive analysis of the sources of the theory of intertextuality in their historical and genre diversity;

- tracing the dynamics of semantic transformations of the idea of intertextuality in the Western humanities in the period from the introduction of the term in the use of humanities to the present time, and to explore the historical background of the theory of intertextuality in Western humanities intertextual trends in cinema and music;

- identifying specific characteristics of cinema and music, concentrating the theory of intertextuality to describe cinema and musical artefacts, describing possible aspects of applying intertextual characteristics to the process of creation (drama, technique, structure, processes, properties, material fixation), reproduction and understanding (nonverbal and verbal interpretation) of cinema and musical works.

The tool of analysis of various phenomena of musical culture is the adaptation to its realities of the critical methodology of postmodernism. The application to different situations of its existence methods of analysis, ascending to the actualised by postmodern linguistics objectified language systems and systems of translation and retransmission of information, seems all the more relevant because the very nature of musical art, nonverbal in nature, provides material for one of the possible areas of application interpretive mind (Striełkowski \& Cheng, 2018). The heuristic potential of postmodernism as a style of thinking in the methodological innovations of the humanities in general and musicology in particular is not fully realised and appreciated.

\section{Results and discussion}

\section{History of development and formation of the intertextuality theory}

Problems of intertextual interactions have long been the subject of research by scholars specialising in literature and linguistics. The introduction of the concept of "intertextuality" has caused a new impetus to research in linguistics, literature and culture studies. Literally from Latin intertextuality means "interweaving of texts, the presence of one text in another." As mentioned above, this concept was first used by French scientist Julia Kristeva (1967). But the founder of the theory of intertextuality is considered to be the Russian scholar Mikhail Bakhtin, who in his work on "another's word" in "his" called a foreign word such that is "every word of another man, not every 
word" (Bakhtin, 1929). He said that the boundaries between one's word and another's could shift, but there was a tense ideological struggle on that boundary. Bakhtin also noted that any foreign language can be given in the text directly and graphically denoted by quotation marks, but usually a number of borrowed words and semi-sentences are hidden in the utterance, so it is difficult to determine the level of foreignness of such an utterance.

In the late 60 s of the $20^{\text {th }}$ century, Bakhtin's ideas were developed in the works of French poststructuralists Yu. Kristeva and R. Bart, who formed a classical expression of the theory of intertextuality (1994). As noted above, Kristeva was the first to use the term "intertextuality" in her article "Bakhtin, word, dialogue, novel" (Kristeva, 1967). She insisted that when analysing the text, it is necessary to consider any expression not as a point (permanent meaning), but as a place of intersection of text planes, as a dialogue between different types of writing - a reader, writer and writing that arose as a result of the collision of the current and the previous cultural context. The authors agree with Kristeva and believe that any text is the result of a modification of any other text, so the new text already exists separately from the author.

Similar ideas about intertextuality in the 1960 s and 1970 sere expressed by R. Barth, who in his essay "The Death of the Author" wrote that the text consists of many other texts and types of writing that come from different cultures and create a relationship between them, dialogue, controversy, parody, etc. (1994). According to the scientist, intertextuality is a sign that an author is no longer the only source of a text. Thus, according to the author, a text can no longer be considered as an autonomous unique formation with its inherent invariable content, once and for all invested by an author-creator of a work. A text is intertextual in nature, because its meaning does not exist within itself, but between the texts, in relation to the text to other source texts, in addition to existing not only before it, but also those that appeared after. It can realise its own meaning only thanks to a reader, because only a reader in his mind can relate a text to the current, previous and future cultural context. Like Kristeva, Barth argued that any text is an intertext.

As can be seen, Kristeva and Barth were at the origins of the development of the theory of intertextuality, but many prominent scientists are involved in the formation of this concept. For example, J. Derrida, whose philosophical views are considered, according to many researchers, the basis of the literary concept of intertextuality. He emphasised that "every text lives among the responses, echoes, inoculations of one text in another", and proposed a new way of philosophical reasoning - deconstruction, the purpose of which is to identify traces of its echoes with other texts, extrasystemic, marginal elements that internally undermine its structure. Derrida (2000) looked at the text from a philosophical point of view and said that every reality - literature, culture, society, history, human consciousness (including an author and a reader) - is textual in its structure, so the interpretation of a text is not just a linguistic phenomenon, it is a concept applied to nonverbal semiotic objects.

Over time, when the doctrine of intertextuality has already begun its active development and gained popularity, the number of scholars and, consequently, the number of opinions on the interpretation of this concept has increased, and in some cases the new concepts differed significantly from those proposed by Kristeva and Barth. A new generation of researchers has criticised poststructuralists for their propensity for abstractionism and remoteness from reality, too philosophical views of the scientific concept, which has led to the lack of development of any appropriate methods of textual analysis within this theory. Followers of the first researchers of intertextuality tried to specify this concept through the connection with the author's intention, the writer's conscious desire to establish a relationship between a text he created and the works of his predecessors. The motive for such changes was the practical use of the concept of intertextuality, 
the broad definition of which prevented its application in the process of text analysis and the identification of cases of interaction between specific texts.

We agree with V.Ye. Chernyavska (2004), who considers intertextuality as a literary device, the special quality of certain texts, which are purposefully focused on the connection with other texts, dialogue with a specific foreign semantic position, which is an exceptional way of meaning and text. After all, intertextuality is inherently a rather narrow concept, so it is appropriate to define it as one of the categories in the sciences with which it intersects.

From the above, it is clear that there are some differences in the interpretation of the concept of intertextuality between the followers of the old and new school of teaching. Therefore, it can be concluded that one of the problems of the studied theory is the uncertainty and lack of unity in its understanding. The authors do not dare to put an end to this dispute, but note that both of these concepts have a right to exist. After all, proponents of a more specific approach to understanding intertextuality do not deny as a fact the integration of any text into a holistic system of human cognition, its obvious connection with the set of linguistic and extralinguistic sign background. While a broad interpretation tends to philosophical generalisations and describes the principles of culture in general, a narrow approach is more relevant for practical research because it offers specific strategies for analysing works in terms of their involvement in the dialogue of texts.

\section{Intertext in audio-visual art: cinema and music}

A film is a form of text in which a large number of semiotic systems are combined. A film is defined as a sequence of frames recorded on film or other material media, which is a photographic or painted image, usually accompanied by a sound sequence (speech, music, noise). Feature film as a type of film is distinguished by the transformed reality of the story, the game and the presence of an expanded system of means of expression. Cinema is one of the most popular, popular and accessible forms of audio-visual fixation of the text, the feature of which is that cinema is both an intertextualised text and a source of intertextuality. That is, the film text itself absorbs the features of other texts, and provides space for integration into future texts.

Cinema is characterised by its own special language, the features of which are intertextuality and a large number of authors. The study of the language of cinema is based on the understanding of language as an open system. Just as the concept of text can be specified exclusively within a sign space, language is a global system of signs. Depending on the means of expression that have different types of texts, units of language may include in addition to purely verbal and signs different from them, including visual, nature. It is proposed to consider a montage frame (phraseepisode) as a unit of cinematic language in the work. The elements of cinematic language include such means of expression as perspective, lighting, colour, sound effects, verbal component. A film text is characterised by the fact that many authors take part in its creation, each of whom contributes to the text - director, screenwriter, cameraman, actors, composer, artist. In this case, the plurality of a sender of a film text correlates with the integral singularity of an addressee. The final dialogue involves two linguistic personalities - an addressee of a film message and a character of a film. The main feature of cinematic language is that each of its elements acquires meaning only in context - this is the main characteristic feature of cinematic feature film.

Cinema in the context of the theory of intertextuality is considered by researchers from different points of view: filming of famous literary heritage and its connection with the original work of art or comic (filming which has become very popular over the past decade) (e.g. "Pride and 
Prejudice", "Harry Potter", "Dark Knight", etc.); parody films, the manifestation of which in the film text is based on allusions to cinematic and television methods of shooting (for example, "Airplane", "Scary movie", "Meet the Spartans", etc.); so-called "Easter eggs", which denote hidden or difficult to find information that is partially or not at all relevant to the original text (for example, in films about archaeologist Indiana Jones, there are "Easter eggs" for the Star Wars franchise); reminiscence or reference is a certain quotation of already known images or works (supporters of this kind of intertextuality in their films are Woody Allen, Quentin Tarantino, etc.); homage - a tribute or confession of love for another movie (for example, in the series "Black Mirror" one of the episodes is a homage to the franchise "Star Trek" in 1966).

A significant contribution to the development of the theory of intertextuality in cinema was made by the Russian historian, philosopher, film critic and philologist M.B. Yampolsky, substantiating in his works the intertextual connections of cinema with the outside world and works of art. The symbolism of cinema, represented by cinematic means, is reduced by M.B. Yampolsky in the rank of its [cinema] main feature, the allusiveness of cinema appears as an integral component of the film text (Byhring \& Knain, 2016). Recognising intertextuality as a global text category, and film text as a complex semiotic semantic unity, it can be concluded that the main way of manifestation of the category of intertextuality can be considered the moment of inclusion of other texts or their elements in a cinematographic work.

Intertextuality is understood as the use of elements of an existing text in the process of creating and functioning of a new one. In a large number of features of intertextuality relevant to the study of film text are the following: mandatory designation in the text of intertextual inclusions and their awareness by an author and an addressee; selection of text inclusions both at the formal level and at the level of meanings and meanings. The typology of intertextual connections of film text is based on the following criteria: source of borrowing (by thematic feature and by correlation with the source); features of marking (according to the degree of marking and the method of marking); type of intertextual links (depending on the borrowed essence, nature and method of expression).

Varieties of intertextual references from the point of view of marking are considered according to the following criteria: 1 ) the degree of marking (maximum marked, medium marked and minimum marked); 2) the method of marking (involving the actor factor, audio, visual image: written text or non-text image). In terms of expression, intertextual references in the film text should be classified based on the nature of the information borrowed, the nature and manner of expression of the reference. According to the criterion of the nature of borrowed information, intertextual connections are divided into meaningful (established to involve the actual side of the source present in the borrowed text of the idea, plot motive), structural (separates the form of the sign from its content and is borrowing the visual solution of the frame) (used in cases of direct citation, as well as when formal and substantive elements are equally important to authors of a film and are involved by them independently of each other). According to their nature (degree of expressiveness), intertextual references are quotations (which in a film text: can be limited to borrowing forms of presentation of the material without involving its content; when reproducing a non-literary source almost exactly repeat its visual, intonational, melodic texture - these are "cinematographic" reminiscences, which are embodied in a film in the form of a genre, plot borrowings and allusions.

Feature film as a type of text (film text) has general text and specific film text characteristics. These characteristics are common to all feature films and therefore can be considered as categories of a film text. The peculiarity of most general text categories of a film (informativeness, unity, 
coherence, semantic completeness, design, ability to interpret) is determined by the two-level structure inherent in cinema (the presence of audio and visual components) and the dominance of the visual component in the film. The principal categories of a film are: intertextuality as a designation of belonging of a film text to the cultural and, first of all, cinematographic tradition; modality as the realisation of the author's beginning in cinema. Unlike the traditional linguistic understanding of modality as a grammatical or semantic category, textual modality in a film is subjective and is a contrast to the objective reflection of reality or conventions of the genre that are generally accepted, established in cinema.

The influence of intertextuality on the musical creativity of the last three decades of the $20^{\text {th }}$ century (the time period with which postmodernism is chronologically associated in Western European and American music) (Ilunina, 2018) turned out to be so serious and significant that it caused changes in the relationship in the triangle: composer (author) - performer - listener. These are new accents that are directly related to interpretation. If before the role of an interpreter belonged primarily to a performer, who always sought an extremely authentic reading of the composer's idea, now it is possible to transfer interpretive functions, on the one hand, to the text of the work, and on the other - to a listener. In the situation that arose, the mission of an author as a carrier of absolute (in the sense of unique, singular) creative beginning has changed. It gradually reduced to the function of a master, who skillfully, ingeniously and with inspiration creates a large cultural text with a combination of sounds.

I. Stravinsky said that "any interpretation reveals first of all the individuality of an interpreter, not an author" (Kaźmierczak, 2019), in the postmodern context suddenly became relevant, despite the rhetorical concern about the "preservation" of the composer's role. Stravinsky questioned the guarantee that a performer would accurately reflect the image of a creator and his features without distortion. It is clear that Stravinsky meant the problem of performing reading of an author's text - an area traditionally associated with the concept of "interpretation". But there are other areas, such as the area of listener perception.

In compositional practice, the use of well-known musical texts (in whole or in part, such as the use of certain musical themes, intonations, rhythmic formulas, etc.) is a creative method that reaches the level of known stylistic orientations. However, the stylistic gradations located on the scale "from general to individual" play an important role here. In the relationship of different texts to the forefront is the stylistic issue. It is the textual comparisons that make it possible to consider the "subtleties" of stylistic work (writing, expression). The concept of "stylistic expression" becomes dominant in the environment of textual interactions. This environment is favourable in that the stylistic "difference" is manifested at the elementary sign level, brought to absolute specificity: this is manifested in the comparison of translations. With the help of discursive analysis, it is possible to objectify in a certain way stylistic categories, the main array of which is hidden under the thickness of the notation. As one of the founders of intertextuality, R. Barth, said: "Language, like some nature, permeates the writer's word, although it does not give it any form and does not even possess it: it is like an abstract circle of common truths; only outside it begins to thicken the originality of the lone writer's word. Language is not so much stock of material as a horizon, that is, both the territory and its borders ... the space of the speech estate". And then he writes directly about style: "Style is human thought in its vertical and separate dimension ... it is the natural "matter" of the writer, his wealth and his prison, style is his loneliness" (Turaeva, 2016).

Using the style of Bart's metaphors, it can be said that when comparing different texts (text models), the authors identify, extract and separate the style from the plot-semantic and semiotic layers. In the discursive analysis of the interaction of "old" and "new" musical-textual material, there 
are stylistic and intertextual aspects of music. The status of "old" texts in the plots of "new" is always an event, because it is basically through them that the semantic "rays" of the work are refracted. However, the content, depending on the forms of use of known material, manifests itself in different ways, i.e. events should be sought where the collision of "old" and "new" texts informs the work of additional information, which raises the information volume of the whole work. Event also oversees the degree of substitution of the meanings of quoted and authentic texts, ensures its mobility and in general makes possible this form of musical creativity.

The composer's practice of translations has a special meaningful accentuation connected with the rethinking of already known musical material. It is the factor of rethinking here that is the coordinating method of discursive analysis. As in the sonata, the thematic transformations of the musical text also have reference representations, however, they are not related to objective reference "schemes", such as sonata-genre, sonata-form, with all the consequences arising in the form of structural relationships with patterns. In thematic transformations of a musical standard is a specific work, its part or in general its separate thematic element.

\section{Analysis of intertextuality problems and possible ways to solve them}

First of all, it is necessary to form the doctrine of intertextuality as a separate direction in linguistics. In the authors' opinion, the linguist of the theory of intertextuality is called by textual (intertextual) analysis of verbal media. But if "classical" textology "originated as a narrowly auxiliary discipline, as the sum of philological techniques for publishing texts" (Klimovich, 2014), then intertextology should be aimed at directly identifying "foreign" text within "its". In the case of a hypothetical possibility of such a discipline as linguistic intertextology, its priority is the rehabilitation of verbal varieties of text. In the current context of the loss of self-identification of the humanities, linguistics has faced the necessity to terminologically defend units of different levels of language. In this regard, the range of linguistic intertextology provides for the inclusion of the following problems.

Determining the status of intertext in the system of language units. In linguistics, there are two language paradigms: system-centric and anthropocentric. The first paradigm puts in the forefront the construction of a clear hierarchy of language levels, with each level having its own units: phoneme, morpheme, token, phrase, sentence, text. In light of the above, there is a problem at what level in the established language hierarchy to place the intertext, as well as what is its basic unit. Contrary to the etymological logic of classifying the intertext as the syntax of a text, it is necessary to remember that "foreign" text is not determined by volume and can be represented as a group of sentences or in one word, remaining a carrier of verbal information. This set of units of intertext has already received a well-established terminology in science - "intertext", defined by K.P. Sidorenko as an "interlevel relational (correlation) segment of the semantic structure of the text - grammatical (morpheme-word-forming, morphological, syntactic), lexical, strophic, compositional - is involved in intertextual relations" (2002). As a result, the intertext occupies a circular position, encircling all levels of language. Anthropocentric paradigm actualises in linguistics Protagoras' judgment "man is the measure of all things", i.e. vocabulary, phonetics, grammar are considered through the prism of human consciousness, so come to the fore communicative processes, language acts and more. In this case, the intertext becomes a kind of spotlight that illuminates the linguistic layer of culture in order to identify patterns of intertextualisation. 
Search for intertext markers and indicators. Recognition of "foreign" text requires to focus on certain indicators, in some cases hidden, in others - evident. A similar evidence/implicitness of intertext was noted by N. Piege-Gro, he said the following:

"Explicitly forms of intertextuality are present in the text evidently; they may be indicated by typographic characters (italics and quotation marks when quoting) or by semantic indicators, such as the name of an author of a work in question, its title, or a name of a character who unambiguously refers to a particular work. When intertextuality is implicit, its indicators are more uncertain and diverse" (P'ege-Gro, 2008).

The issue of labelling intertextual links is fundamental to their identification by the audience. This is especially true of borrowings, as a result of which the source text is modified, as well as links assimilated by the film. There are several levels of perception of intertextual connections. Just as Yu.S. Stepanov highlights the superficial and deep meaning of the concept, it is appropriate to talk about the initial perception and subsequent understanding of intertextual borrowing. Communication with the source may be superficial (Chaemsaithong \& Kim, 2018). In this case, only the part of the borrowed text that is reproduced or activated by the link is violated; non-identification of links of this kind by the audience does not entail misunderstanding of the whole film or its significant segments.

Global intertextual relationships that are established within the whole film text, as a rule, have several levels of meaning and form a relationship with the source at the level of a key idea. Failure to establish such connections by the viewer leads to serious semantic gaps and possibly a misunderstanding of the concept of the whole film. Intertextual relations established in the film text have a number of characteristics due to the unique means that cinema has in the field of marking and expression of links, and which, in turn, determine the specifics of sources of borrowing in the film text.

The problem of using existing musical texts in the work is next to the problem of intertextuality in music, which in modern art has acquired general significance. V. Rudnev in his work "Away from reality" wrote: "The older the text, the more informative it is, as it retains information about its former potential perceptions" (Homidova, 2019). This thesis is interesting, and in musical texts has a special status. As in verbal texts, the discourse of this status is determined primarily by the contextual position of the text in the historical and stylistic consideration, as well as its significance as a semantic fact. However, musical texts in which abstraction is limited only by symbolic conventionality, while in verbal texts conventionality penetrates the semantic level, requires special understanding, because the comparison of the text with its significance in the timeline causes additional difficulties in creating meaning. The degree of informativeness of "older" and "younger" texts, of course, is directly proportional to their time scale. However, such an approach is relevant only if these texts become a "living" reminder of themselves, identify themselves, as well as subject to certain relationships, the relationship between these texts. The informativeness of the "old" texts exceeds the informativeness of the "new" ones not in its abstractinformative fact, but in the context of the perception of a text in the cultural-historical context (Bik Ngai, 2020; Thielemann, 2020).

Thus, the theory of intertextuality will logically be, in the authors' opinion, divided into three segments, which will be based on different humanities: interpersonal dialogue - culture studies and philosophy; intertextual semiotic dialogue - art disciplines, literary studies and semiotics; intertextual linguistic dialogue - linguistics. And if the existence of linguistic textology is possible, then it is quite fair to talk about cultural, semiotic, literary, art intertextology. The existence of such a division does not imply demarcation lines within the theory of intertextuality, 
the isolation of the researcher within his complex of problems. For example, linguistic intertextology, as the authors see it, can become a solid methodological basis for the general theory of intertextuality, and an intertextologist from linguistics - a practitioner who produces intertextual material, later analysed in various disciplines.

\section{Conclusions}

The issue of intertextual relations in recent decades has been the object of special attention of researchers in various fields of humanities: philosophers, linguists, literary critics, culture scientists. According to most scholars, one of the most difficult aspects of any text is its intertextual connections. Recently, an increasing number of works are devoted to "dialogue" and "polyphony" in a text, "foreign word" in a text, "dialogue" of texts or intertextuality. After analysing the use of the term "intertextuality", it can be concluded that the meaning of this concept varies significantly depending on the theoretical assumptions that guide the researcher. Intertextuality is understood as the ratio of text and genre, the interaction of all produced proto-texts included in the text, as the visible presence of one text in another. It extends from extremely wide limits of use - to narrow. In a narrow version, this concept is limited to deliberately used and marked connections of the text with other texts and becomes suitable for the practice of text analysis, in particular, for application to texts of classifications of intertextual means. Moreover, in the authors' opinion, the concept of intertextuality is promising for the analysis of cultural texts in a broad sense - as sign complexes of any semiotic system, not just verbal. This approach allows exploring musical works, works of fine art, film texts, print advertising and other cultural objects.

It can be concluded that intertextuality is understood in modern linguistics as the correlation of texts, as a place of intersection of text planes. The problem of intertextuality is closely connected in literary studies with the problem of sources, influences and imitations, but is not reduced to it. When studying intertextual connections, the text should be approached not from the point of view of the author's intention, but from the point of view of what got into the text, what recipients will see in it, and what associations these inclusions can evoke in it.

\section{References}

Arnold, I.V. (1999). Semantics. Stylistics. Intertextuality. St. Petersburg: Publishing house of St. Petersburg State University.

Bakhtin, M.M. (1929). Problems of Dostoevsky's creativity. Leningrad: Priboy.

Bart, R. (1994). Selected works: Semiotics. Poetics. Moscow: Progress.

Bazhenova, E.A. (2003). Stylistic Dictionary of the Russian Language. Moscow: Nauka.

Bik Ngai, C.S., Gill Singh, R., \& Kwan, B.S.C. (2020). A comparative study of the linguistic manifestations of intertextuality in corporate leaders' messages of global corporations in the US and China. English for Specific Purposes, 6o, 65-84.

Byhring, A.K., \& Knain, E. (2016). Intertextuality for Handling Complex Environmental Issues. Research in Science Education, 46, 1-19.

Chaemsaithong, K., \& Kim, Y. (2018). From narration to argumentation: Intertextuality in two courtroom genres. Lingua, 203, 36-50. 
Chernyavskaya, V.E. (2004). Intertext and interdiscourse as the implementation of textual openness. Questions of Cognitive Linguistics, 1, 106-115.

Derrida, J. (2000). Letter and distinction. Moscow: Nauka.

Fateeva, N.A. (2006). Intertext in the world of texts. Counterpoint to intertextuality. Moscow: Nauka.

Genette, G. (1999). Figures. Paris: Seuil.

Homidova, M.F. (2019). The problem of intertextuality in modern linguistics. Central Asian Problems of Modern Science and Education, 3(4), 259-263.

Kaźmierczak, M. (2019). Intertextuality as Translation Problem: Explicitness, Recognisability and the Case of "Literatures of Smaller Nations". Russian Journal of Linguistics, 23(2), 362-382.

Klimovich, N.V. (2014). Phenomenon of Intertextuality in Translation Studies. Journal of Siberian Federal University. Humanities \& Social Sciences, 2, 255-264.

Kristeva, J. (1967). Bakhtine, le mot, le dialogue et le roman. Critique, 239, 438-465.

Kuzmina, N.A. (2004). Intertext and its role in the evolution of poetic language. Yekaterinburg: Publishing house of the Ural University.

Litvinenko, T.E. (2008). Intertext and its linguistic foundations: on the material of Latin American literary texts. Irkutsk: IGLU.

P'ege-Gro, N. (2008). Introduction to the theory of intertextuality. Moscow: Editorial URSS.

Plett, H. (1991). Intertexualities. Berlin: Soringer.

Riffaterre, M. (1988). New in Foreign Linguistics: Linguistic Stylistics. Criteria for stylistic analysis, 9, 126-141.

Sidorenko, K.P. (2002). Intertext interpreters in the "Dictionary of Pushkin's aphorisms" In: Collection of scientific articles to the $60^{\text {th }}$ anniversary. Moscow: Azbukovnik. 316-324.

Striełkowski W., \& Cheng J. (2018). Advances in Social Science, Education and Humanities Research. Amsterdam: Atlantis Press.

Thielemann, N. (2020). Allusive talk - Playing on indirect intertextual references in Russian conversation. Journal of Pragmatics, 155, 123-143.

Turaeva, Z. (2016). Intertextuality: Ariadne's Thread in the Exploration of Literature. Russian Journal of Linguistics, 20(3), 31-42. 